\title{
Fuel-Cladding Interaction Between U-Pu-Zr Fuel and $\mathrm{Fe}$
}

\author{
ASSEL AITKALIYEVA, JAMES W. MADDEN, BRANDON D. MILLER, \\ CYNTHIA A. PAPESCH, and JAMES I. COLE
}

\begin{abstract}
This work investigates fuel-cladding chemical interaction (FCCI) between U-25Pu-14Zr (in wt pct) fuel and pure $\mathrm{Fe}$ at elevated temperatures, understanding of which is critical for evaluation of the fuel performance. Phases and microstructure formed in the quaternary uranium-plutonium-zirconium-iron ( $\mathrm{U}-\mathrm{Pu}-\mathrm{Zr}-\mathrm{Fe}$ ) system were characterized using the transmission electron microscopy technique. Phases formed within the FCCI layer were identified using selective area electron diffraction (SAED) analysis as $\mathrm{Fe}_{2} \mathrm{U}(\mathrm{Fd}-\mathrm{m}), \mathrm{Fe}_{2} \mathrm{Zr}$ (Fd-3m), $\alpha-\mathrm{U}(\mathrm{Cmcm}), \mathrm{Fe}_{2} \mathrm{Pu}(\mathrm{Fd}-3 \mathrm{~m}), \beta$-Pu $(\mathrm{C} 12 / \mathrm{m} 1)$, and $\beta$ - $\mathrm{Zr}(\mathrm{Im}-3 \mathrm{~m})$.
\end{abstract}

DOI: $10.1007 / \mathrm{s} 40553-015-0059-4$

(C) ASM International (ASM) and The Minerals, Metals \& Materials Society (TMS) 2015

\section{INTRODUCTION}

Metallic fuels are one of the most promising candidates for next generation fast reactors. They have the advantage of simple fabrication, high burn-up, good thermal response, and relatively simple recycling using melt refining or electro-refining processes. ${ }^{[1]}$ Uranium-plutonium-zirconium (U-Pu-Zr) alloys comprise the leading metallic fuel candidates for fast reactor and transmutation fuel applications. However, metallic fuels have several disadvantages as compared to alternative fast reactor fuels, such as an affinity for fuel-cladding chemical interaction (FCCI).

Solid-state diffusion under gradients of temperature and concentration during irradiation causes constituent redistribution in metallic fuels, which affects homogeneity of the fuel alloy. The inhomogeneity of fuel alloys can lead to phase transformations, changes in solidus temperature, and local changes in fissile atom density ${ }^{[2]}$ This can alter mechanical and physical properties of the fuel alloy, and modify behavior and performance of the fuel. Potential eutectic melting of the interaction products, formed as a result of FCCI, at temperatures lower than the melting temperature of the fuel is a limiting factor in the performance of the metallic fuel. Additionally, formation of an interaction layer can reduce cladding thickness and decreases its load-bearing capability, consequently decreasing the life of a fuel-bearing element. ${ }^{[3]}$

Understanding fuel constituent redistribution that alters alloy composition and affects fuel performance is imperative for safe operation of the reactor. However, to comprehend irradiation-induced changes in $\mathrm{U}-\mathrm{Pu}-\mathrm{Zr}$

ASSEL AITKALIYEVA, CYNTHIA A. PAPESCH, and JAMES I. COLE, Materials Scientists, JAMES W. MADDEN, Senior Microscopist, and BRANDON D. MILLER, Nuclear Engineer, are with the Idaho National Laboratory, P.O. Box 1625, M.S. 6188, Idaho

Falls, ID 83415-6188. Contact e-mail: assel.aitkaliyeva@inl.gov

U.S. Government Work. Not Protected by U.S. Copyright.

Manuscript submitted June 23, 2015.

Article published online November 19, 2015 alloys and consequent FCCI, the phases and microstructure of unirradiated fuels should be characterized first. Out-of-pile annealing tests on diffusion couples have been conducted to investigate FCCI behavior between $\mathrm{U}-\mathrm{Zr}$ and $\mathrm{U}-\mathrm{Pu}-\mathrm{Zr}$ fuel alloys and $\mathrm{Fe}, \mathrm{Fe}-12 \mathrm{Cr}$, and HT-9 cladding. ${ }^{[-11]}$ The most inclusive study of quaternary U-Pu-Zr-Fe system at $973 \mathrm{~K}\left(700{ }^{\circ} \mathrm{C}\right)$ has been conducted using thermal analysis and energy-dispersive spectroscopy (EDS) in scanning electron microscope (SEM).${ }^{[9]}$ However, there are issues associated with the characterization of $\mathrm{Pu}$ phases using EDS such as unavailability of $\mathrm{U}$ and $\mathrm{Pu}$ standards for appropriate EDS calibration, spatial resolution, magnification-dependent sensitivity of the technique, and overlaps of $U$ and $\mathrm{Pu}$ EDS peaks, all of which restrict accurate quantitative chemical analysis of $\mathrm{Pu}$-based phases in SEM. To address the limitations of SEM analysis, detailed structural and chemical composition analysis of formed complex phases needs to be conducted in transmission electron microscope (TEM). In this work, transmission electron microscopy has been implemented to attain better understanding of compatibility between $\mathrm{U}-\mathrm{Pu}-\mathrm{Zr}$ fuel and $\mathrm{Fe}$ cladding and investigate diffusion zone structure at the fuel-cladding interface.

\section{MATERIALS AND METHODS}

A fuel alloy with nominal composition of $\mathrm{U}-25 \mathrm{Pu}-14 \mathrm{Zr}$ (in wt pet) was arc cast in an inert atmosphere glove box using a drop-casting technique. After casting, the cylindrical alloy was sectioned into several pieces. The surfaces of pure Fe $(99.995 \mathrm{pct}$ purity, obtained from Alfa Aesar, Ward Hill, MA) cladding and fuel slug were polished through a $3 \mu \mathrm{m}$ diamond solution to a mirror polish. The fuel slug was placed in contact with Fe cladding material and compressed in a Kovar steel device, lined with tantalum foil on the interior to prevent an undesirable reaction between diffusion couples and the jig. 


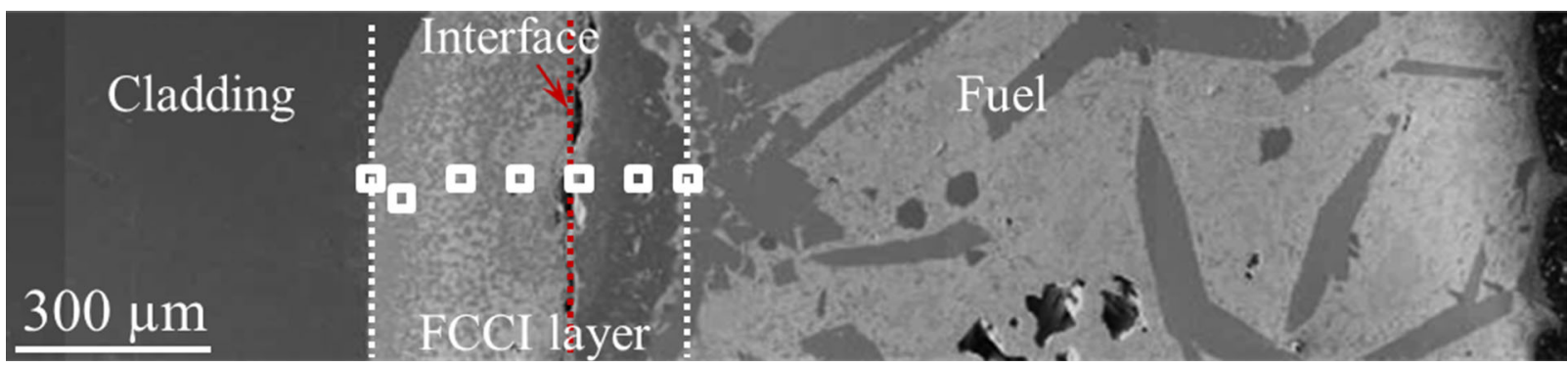

Fig. 1 - Overview of the cladding, formed fuel-cladding interaction layer, and fuel after annealing at $973 \mathrm{~K}$ ( $\left.700{ }^{\circ} \mathrm{C}\right)$. Two white dot lines depict the FCCI layer, and red dot line shows the location of the initial fuel-cladding interface. White rectangular boxes identify approximate location of the lift-outs prepared from the FCCI region. Scale bar denotes $300 \mu \mathrm{m}$ (Color figure online).

The diffusion couple was placed in a furnace and annealed at $973 \mathrm{~K}\left(700{ }^{\circ} \mathrm{C}\right)$ for $75 \mathrm{~h}$ under continuous argon flow. Annealing temperature was selected to simulate normal fuel operating temperatures $[823 \mathrm{~K}$ to $1223 \mathrm{~K}\left(550{ }^{\circ} \mathrm{C}\right.$ to $\left.\left.950{ }^{\circ} \mathrm{C}\right)\right]$. Other diffusion couples were annealed at temperatures ranging from $823 \mathrm{~K}$ to $1223 \mathrm{~K}\left(550{ }^{\circ} \mathrm{C}\right.$ to $\left.950{ }^{\circ} \mathrm{C}\right)$ and the results from those experiments will be published at a later date. In addition to varying temperatures, fuel compositions ranged from 10 at. pct $\mathrm{Zr}$ to 40 at. pet $\mathrm{Zr}$ and from 20 at. pet $\mathrm{Pu}$ to 30 at. pct $\mathrm{Pu}$. However, this manuscript concentrates on the fuel composition containing 30 at. pct $\mathrm{Zr}$ and 20 at. pct $\mathrm{Pu}$. The varying $\mathrm{Pu}$ and $\mathrm{Zr}$ compositions were selected to investigate the influence of these elements on phase formation and constituent migration.

Note that the formation of oxides on the initial interface is likely, since even ultra-high purity argon can contain oxygen and other reacting gases. Therefore, phases formed upon heat treatment could have been stabilized by impurities. Immediately after annealing, the assembly was quenched in water to preserve the phases formed during heat treatment. The diffusion couple was then removed from the compression device, embedded in epoxy, and polished through a $3 \mu \mathrm{m}$ diamond solution prior to analysis.

Cross-sectional specimens for transmission electron microscopy (TEM) were prepared in a FEI QUANTA 3D field emission gun (FEG) dual beam-focused ion beam/scanning electron microscope (FIB/SEM) using a lift-out approach. Prior to TEM specimen preparation, surface of the diffusion couple was examined in SEM to determine the exact location of the fuel-cladding interaction zone and perform initial examination of the formed microstructure. To reduce charging, a layer of Pd coating was applied to the sample surface prior to analysis in SEM. Specimens for TEM were characterized at $200 \mathrm{kV}$ in a JEOL JEM 2010 TEM equipped with Bruker Quantax 200 Esprit 1.9 software and a Bruker 133 silicon drift detector.

Seven cross-sectional specimens were prepared from the FCCI region, shown in Figure 1, and characterized in TEM. Several lift-outs were prepared to ensure thorough characterization and identification of all phases. The lamella had approximate dimensions of $15 \times 10 \times 0.1 \mu \mathrm{m}^{3}$. Identification of formed phases was conducted by comparing experimental selective area diffraction (SAD) patterns to simulated patterns from published crystal structures produced using JEMS software. ${ }^{[12]}$ In addition, d spacing of each diffraction pattern was measured and compared to the published crystallographic data. The data from two cross-sectional lift-outs are provided in this work, since the phases present in the other lift-outs were consistent with data shown here.

\section{RESULTS AND DISCUSSION}

Figure 1 shows an overview of the diffusion couple, in which the formed FCCI layer has been identified with white dot lines. The acquired micrographs and X-ray maps revealed substantial diffusion of the fuel into the cladding that resulted in the formation of a pronounced FCCI layer. The width of FCCI layer was non-uniform with average value of about $454 \pm 32 \mu \mathrm{m}$.

Figure 2 shows elemental X-ray maps and corresponding scanning transmission electron micrograph collected from the first lift-out. EDS point scans were collected but not quantified due to unavailability of standards for transuranic elements. X-ray maps depicting spatial distributions of various elements were collected by individually mapping characteristic X-rays from each element of interest with the EDS spectrometer in the TEM. Each map was adjusted for contrast and brightness to emphasize spatial variations in the intensity. Brighter areas in each map represent higher concentrations of the element of interest than less bright areas in the same map. Note that equally bright areas in different maps do not represent comparable concentrations due to this adjustment. Elemental X-ray maps shown in Figure 2 revealed segregation of $\mathrm{U}$ with $\mathrm{Pu}$ in the matrix, Fe with $\mathrm{U}, \mathrm{Fe}$ with $\mathrm{Zr}$ in globular features, and $\mathrm{Zr}$ in the lightest feature shown in the bottom-left corner of the micrograph. This suggests formation of four distinctive phases within the formed FCCI region.

Previously conducted phase diagram evaluations show that in the fuel operating temperatures $823 \mathrm{~K}$ to $1223 \mathrm{~K}\left(550{ }^{\circ} \mathrm{C}\right.$ to $\left.950{ }^{\circ} \mathrm{C}\right)$ and specifically at $973 \mathrm{~K}$ $\left(700{ }^{\circ} \mathrm{C}\right)$, selected in this study, a number of different phases can form in U-Pu-Zr-Fe system. ${ }^{[6-9,13]}$ Figure 3 shows isothermal sections for three ternary subsystems at $973 \mathrm{~K}\left(700{ }^{\circ} \mathrm{C}\right)$. Different phases can form in Fe-U-Pu subsystem, such as $\mathrm{FeU}_{6}, \mathrm{Fe}_{2} \mathrm{U}, \mathrm{Fe}_{2} \mathrm{Pu}, \beta$-U, $\eta, \alpha-\mathrm{Fe}$, and bec phase, also known as $(\mathrm{U}, \mathrm{Pu}) \mathrm{ht}$. The 

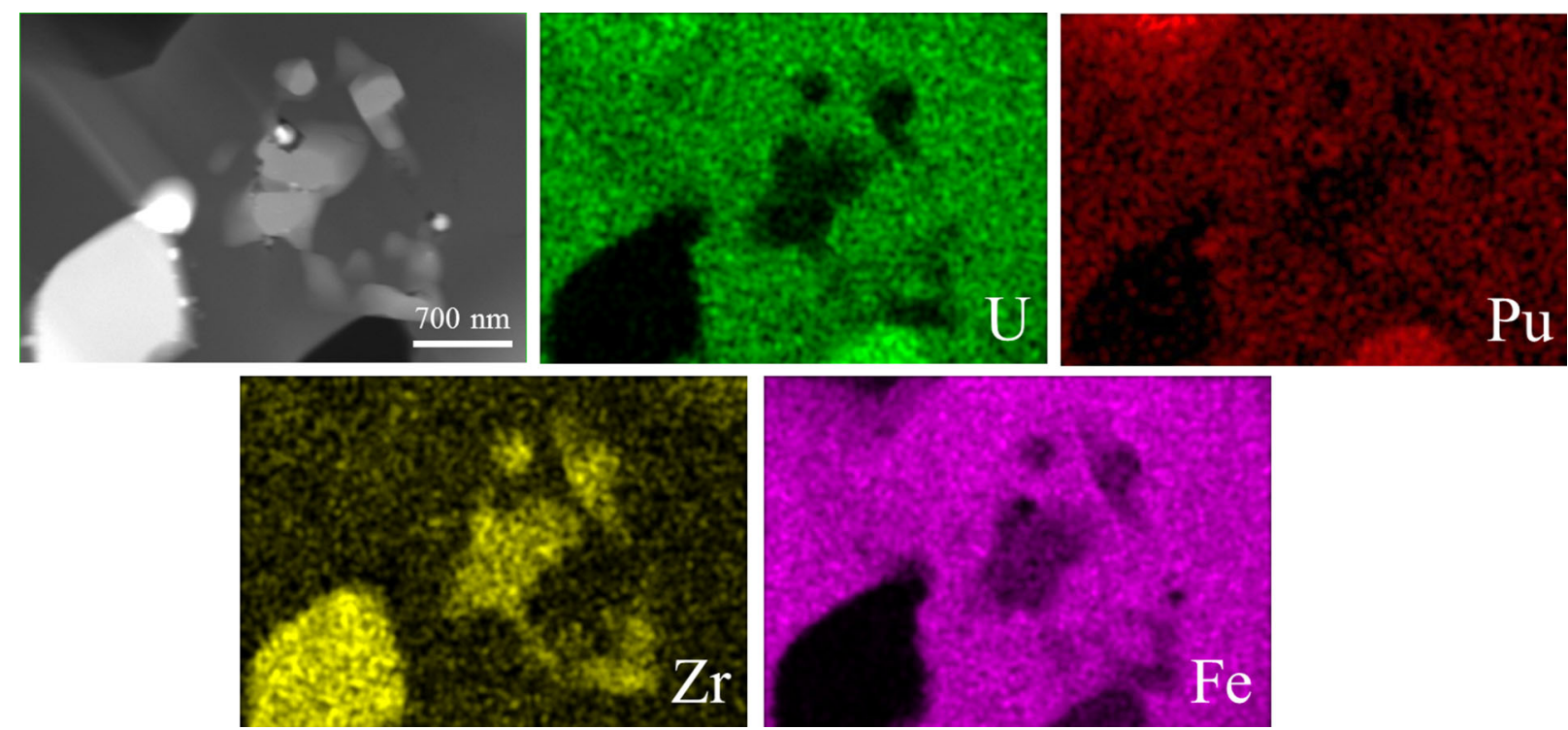

Fig. 2-Scanning transmission electron micrograph and corresponding X-ray maps of the phases formed between U-25Pu- $14 \mathrm{Zr}$ fuel and Fe cladding upon heat treatment at $973 \mathrm{~K}\left(700^{\circ} \mathrm{C}\right)$. Scale bar denotes $700 \mathrm{~nm}$.

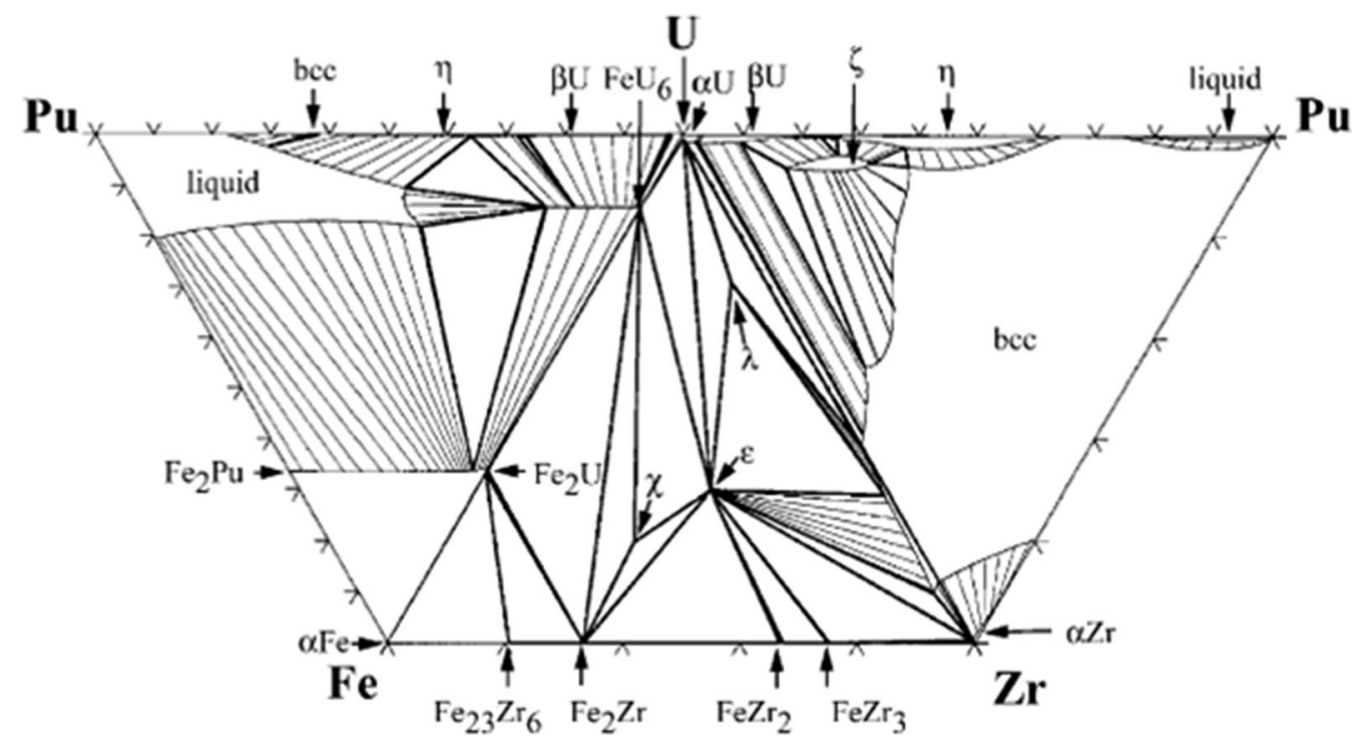

Fig. 3-Assessed isotherms for the ternary Fe-U-Pu, Fe-U-Zr, and Pu-U-Zr systems at $973 \mathrm{~K}\left(700^{\circ} \mathrm{C}\right)$. Reprinted from Ref. [9].

$\mathrm{Fe}_{2} \mathrm{Pu}$ phase has three polymorphic forms: cubic Laves phase of the C15-type, hexagonal Laves phase of the $\mathrm{MgNi}_{2}$-type, and cubic phase that is stable above $1313 \mathrm{~K}\left(1040^{\circ} \mathrm{C}\right)$. The Laves phase $\mathrm{Fe}_{2} \mathrm{U}$ has the C15-type cubic structure, and $\mathrm{FeU}_{6}$ has the $\mathrm{MnU}_{6}$-type tetragonal structure.

The phases that can form in $\mathrm{Fe}-\mathrm{U}-\mathrm{Zr}$ subsystem are $\alpha$-Fe, $\alpha$-U, $\alpha-\mathrm{Zr}, \mathrm{Fe}_{2} \mathrm{Zr}, \mathrm{FeZr}_{2}, \mathrm{Fe}_{23} \mathrm{Zr}_{6}, \mathrm{FeZr}_{3}, \mathrm{Fe}_{2} \mathrm{U}$, $\mathrm{FeU}_{6}, \chi, \varepsilon$, and $\lambda$. The $\mathrm{Fe}_{2} \mathrm{Zr}$ phase can exist in cubic C15-type and hexagonal C36-type forms. The tetragonal $\mathrm{FeZr}_{2}$ phase has a narrow temperature range from $1053 \mathrm{~K}$ to $1224 \mathrm{~K}\left(780{ }^{\circ} \mathrm{C}\right.$ to $\left.951^{\circ} \mathrm{C}\right)$ and orthorhombic $\mathrm{FeZr}_{3}$ phase occurs below $1124 \mathrm{~K}\left(851^{\circ} \mathrm{C}\right)$. The cubic $\mathrm{Fe}_{23} \mathrm{Zr}_{6}$ phase is not in equilibrium as it is stabilized by oxygen. The phases reported in $\mathrm{Pu}-\mathrm{U}-\mathrm{Zr}$ system include $(\mathrm{U}, \mathrm{Pu}) \mathrm{ht}, \alpha-\mathrm{Zr}, \alpha-\mathrm{U}, \beta-\mathrm{U}, \eta$, and $\zeta$. The hexagonal $\delta$ - $\mathrm{UZr}_{2}$ phase has an $\mathrm{AlB}_{2}$-type structure, is non-stoichiometric, and should have extensive solid solubility for plutonium. The $\zeta-(\mathrm{U}, \mathrm{Pu})$ phase belongs to the $R-3 m$ space group with 58 atoms in the primitive unit cell and 10 atoms in the asymmetric unit. The $\zeta$ is stabilized by the presence of $\mathrm{Zr}$.

The experimental work conducted by Nakamura et al., confirmed the formation of $\mathrm{Fe}_{2} \mathrm{Zr}, \mathrm{Fe}_{2} \mathrm{U}, \mathrm{Fe}(\mathrm{Pu}$, $\mathrm{U})_{6}, \quad \lambda$ phase $\left(\mathrm{Fe}_{0.06} \mathrm{U}_{0.69-0.73} \mathrm{Zr}_{0.21-0.25}\right) \quad \chi$ phase $\left(\mathrm{Fe}_{0.5} \mathrm{U}_{0.18} \mathrm{Zr}_{0.32}\right), \quad \varepsilon$ phase $\left(\mathrm{Fe}_{0.33} \mathrm{U}_{0.17-0.34} \mathrm{Zr}_{0.33-0.5}\right)$, and solid solution consisting of $\gamma-\mathrm{U}, \varepsilon-\mathrm{Pu}$, and $\beta-\mathrm{Zr}$ in quaternary U-Pu-Zr-Fe system. ${ }^{[9]}$ They have also observed globular precipitates a few microns in diameter, which after electron probe micro-analyzer (EPMA) examination was assumed to be $\alpha-\mathrm{Zr}$ stabilized by oxygen. ${ }^{[9]}$ In addition, a Pu-rich phase with up to 90 
at. pct $\mathrm{Pu}$ was noted but not identified. All phases were identified using X-ray mapping and EDS point scan analysis, which does not provide any crystallographic information. However, based on their observations, the $\mathrm{Fe}(\mathrm{Pu}, \mathrm{U})_{6}, \mathrm{Fe}_{2} \mathrm{Zr}, \mathrm{Fe}_{2} \mathrm{U}$, and $\chi$ phases should be in equilibrium with a liquid phase, and $\mathrm{Fe}(\mathrm{Pu}, \mathrm{U})_{6}$ and $\chi$ in equilibrium with the $\lambda$ phase. ${ }^{[9]}$
Based on the segregation of the elements in X-ray maps, initial phase identification was conducted by consulting existing ternary phase diagrams. The Fe-Zr-enriched phases could correspond to $\mathrm{Fe}_{2} \mathrm{Zr}$, $\mathrm{FeZr}_{2}, \mathrm{Fe}_{23} \mathrm{Zr}_{6}$, and $\mathrm{FeZr}_{3}$. The Fe-U-enriched region could be either $\mathrm{Fe}_{2} \mathrm{U}$ or $\mathrm{FeU}_{6}$. The Zr-enriched precipitate can be $\alpha-\mathrm{Zr}$ or $\beta-\mathrm{Zr}$. The matrix can correspond to
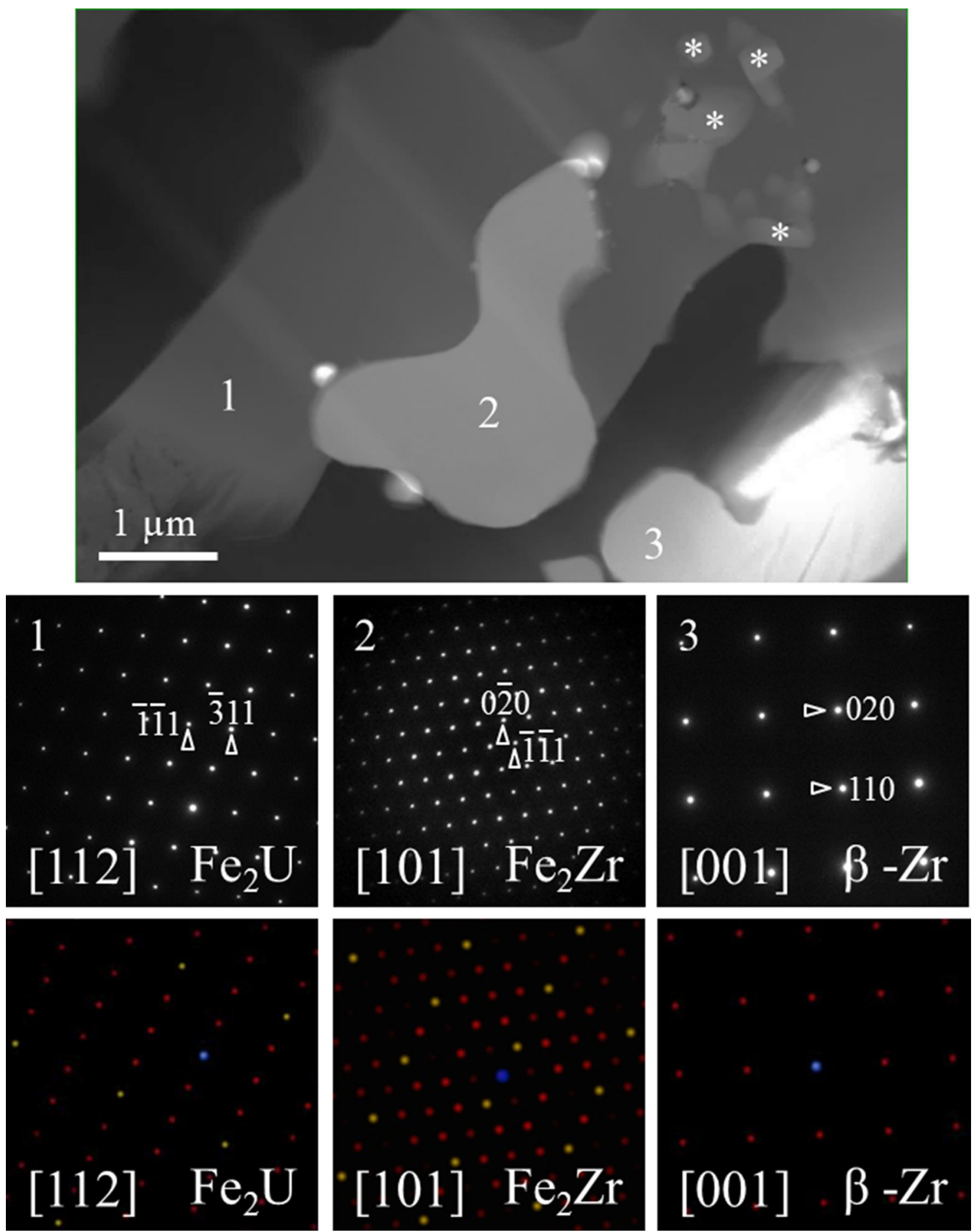

Fig. 4-STEM micrograph acquired from the FCCI layer and corresponding experimental (top row) and simulated SAED patterns (bottom row). Scale bar denotes $1 \mu \mathrm{m}$. The asterisk denotes other $\mathrm{Fe}_{2} \mathrm{Zr}$ phases identified in the micrograph. 
(U, Pu)ht, $\zeta-(\mathrm{U}, \mathrm{Pu}), \alpha-\mathrm{U}$, or $\beta$-U. Selective area diffraction (SAD) patterns of phases shown in Figure 3 were collected, analyzed, and are shown in Figure 4. The Fe-U-enriched phase was identified as $\mathrm{Fe}_{2} \mathrm{U}$, while $\mathrm{Fe}-\mathrm{Zr}$ phase corresponds to $\mathrm{Fe}_{2} \mathrm{Zr}$, and $\mathrm{Zr}$-enriched precipitate is consistent with $\beta$-Zr. Due to the varying FIB milling rates and subsequent specimen thickness variation, the $\mathrm{Pu}-\mathrm{U}$-enriched matrix was not sufficiently thin for SAD analysis; therefore, identification of the Pu-U-enriched phase has not been conducted.

Multiple cross-sectional TEM specimens containing $\mathrm{U}-\mathrm{Pu}$-enriched matrix have been prepared in the FIB tool but due to differential thinning of diverse phase constituents in these multi-component diffusion couples, some U-Pu-enriched phases were not sufficiently thin to acquire SAD patterns. Since both $\mathrm{U}$ and $\mathrm{Pu}$ have larger atomic masses as compared to other elements in these samples, U-Pu-enriched phases thin at a much slower rate. In addition, Pu-enriched phases oxidized more rapidly during specimen transfer between instruments than other phases within prepared lamella. In some cases, when U-Pu matrix was thinned more compared to the other phases within same lamella, rapid oxidation of the matrix leads to the U-Pu matrix transformation into a brittle and highly unstable phase upon exposure to air for short periods of time (20 minutes or less). Because of these issues, identification of $\mathrm{U}-\mathrm{Pu}$-enriched phases in TEM has not been conducted. Further work will be conducted to overcome these issues.

Formation of $\mathrm{Zr}$-enriched precipitates is not an anticipated phenomenon, as the existing phase diagrams

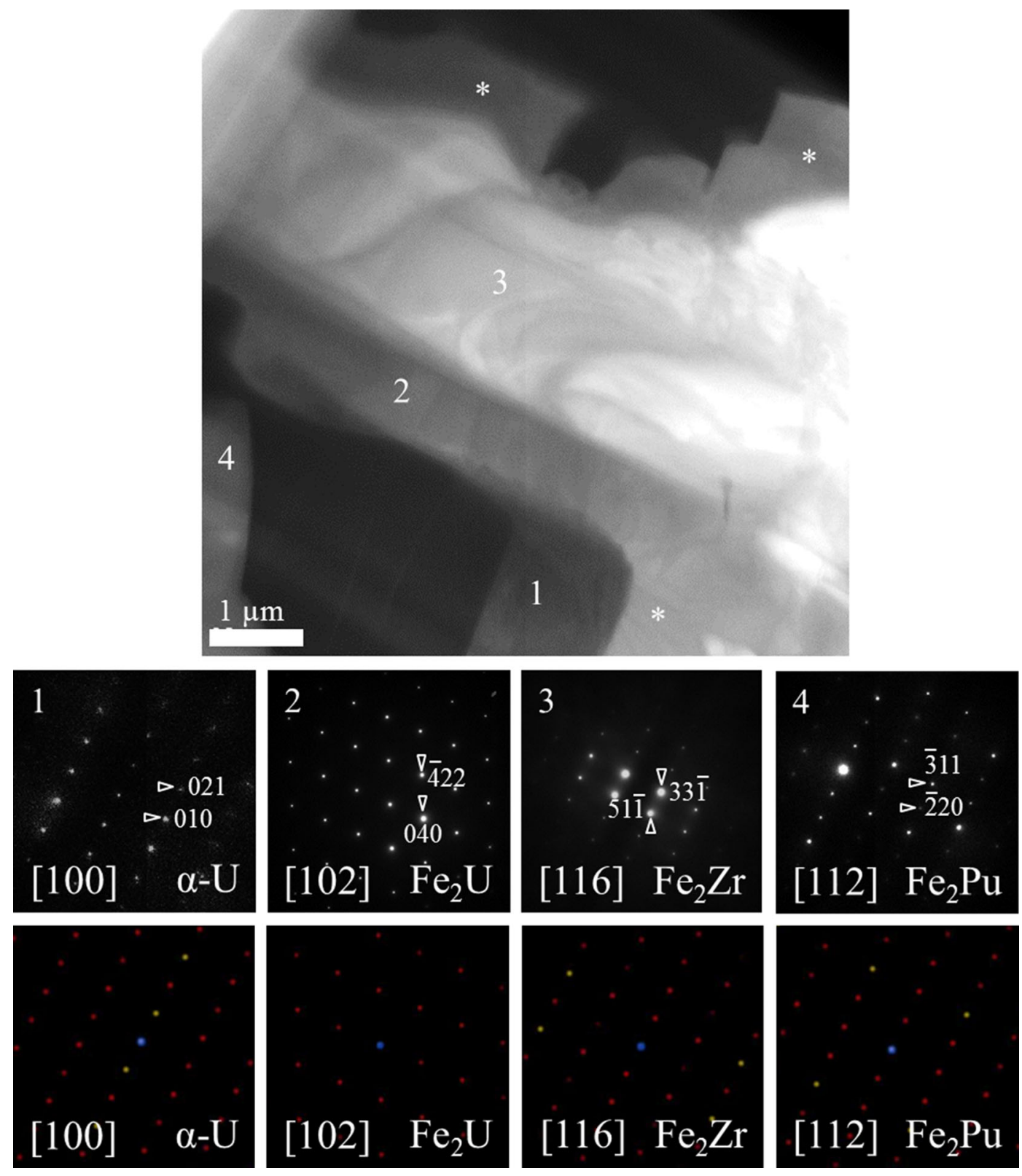

Fig. 5- Transmission electron micrograph acquired from the first lift-out and corresponding experimental (top row) and simulated SAED patterns (bottom row). Scale bar denotes $1 \mu \mathrm{m}$. The asterisk denotes the location of $\mathrm{Fe}_{2} \mathrm{U}$ phase identified in the micrograph. 
do not predict the formation of $\mathrm{Zr}$ precipitates in the alloys of interest. The Zr-rich precipitates, stabilized by dissolved impurities such as $\mathrm{N}, \mathrm{O}$, and $\mathrm{C}$, have been observed in a variety of transmutation fuels. ${ }^{[14-20]}$ In previous studies, these $\mathrm{Zr}$-rich precipitates were assumed to be $\alpha-\mathrm{Zr}$ that formed during alloy preparation because of the interstitial impurities present in the feedstock. ${ }^{[14]}$ Our previous investigation of the U-Pu- $\mathrm{Zr}$ fuel showed the formation of $\mathrm{Zr}$ precipitates in the vicinity of the specimen surface. ${ }^{[20]}$ It is believed that migration of zirconium to the surface of the sample during annealing leads to the separation of $\mathrm{Zr}$ phase from the matrix and formation of a thin layer on the surface of the fuel. ${ }^{[15]}$ Formation of this oxygenated surface upon exposure of the sample to air combined with migration of $\mathrm{Zr}$ toward the oxygen upon heating of the specimen results in formation of the $\alpha-Z r .{ }^{[15]}$ However, in the diffusion couple under observation, only $\beta$-Zr phase has been observed. Formation of face-centered cubic (fcc) $\mathrm{Zr}$, as opposed to $\alpha-\mathrm{Zr}$, has been noted in the work performed by Janney et al. ${ }^{[19]}$. It is possible that impurities such as $\mathrm{N}$ are responsible for the observed $\beta-\mathrm{Zr}$ as the impurities most likely acted as a stabilizing element.

Figure 5 shows bright-field (BF) transmission electron micrograph of the phases formed at the bottom of the second lift-out and experimental SAD patterns corresponding to these phases. Numbers provided in the micrograph indicate location of different phases, which were identified as $\alpha-\mathrm{U}, \mathrm{Fe}_{2} \mathrm{U}, \mathrm{Fe}_{2} \mathrm{Zr}$, and $\mathrm{Fe}_{2} \mathrm{Pu}$. Simulated electron diffraction patterns are provided at the bottom of Figure 5 for reference. The phase with lightest contrast in Figure 5 corresponds to $\mathrm{Fe}_{2} \mathrm{Zr}$, with $\mathrm{Fe}_{2} \mathrm{U}$ phase forming in its immediate vicinity.

Phase constituents developed in the second lift-out during annealing of the diffusion couple were analyzed using X-rays collected with EDX spectrometer. To determine spatial distribution of elements, EDX maps and scanning transmission electron micrograph were correlated and are provided in Figure 6. The elemental constituents can be classified into several groups in which they exhibit similar behavior and segregate into common phases. Qualitative examination of the STEM micrograph and X-ray maps shown in Figure 6 suggests the segregation of $\mathrm{U}$ with $\mathrm{Fe}, \mathrm{U}$ with $\mathrm{Pu}$, and $\mathrm{Fe}$ with $\mathrm{Zr}$. These phases were identified as $\mathrm{Fe}_{2} \mathrm{U}, \mathrm{Fe}_{2} \mathrm{Zr}$, and $\beta$-Pu. Indexed experimental SAD patterns of phases identified in the second lift-out and simulated electron diffraction patterns are provided in Figure 7. The overlap of $\mathrm{U}$ and $\mathrm{Pu}$ EDS peaks can be attributed to the observed segregation between $\mathrm{U}$ and $\mathrm{Pu}$, as shown in
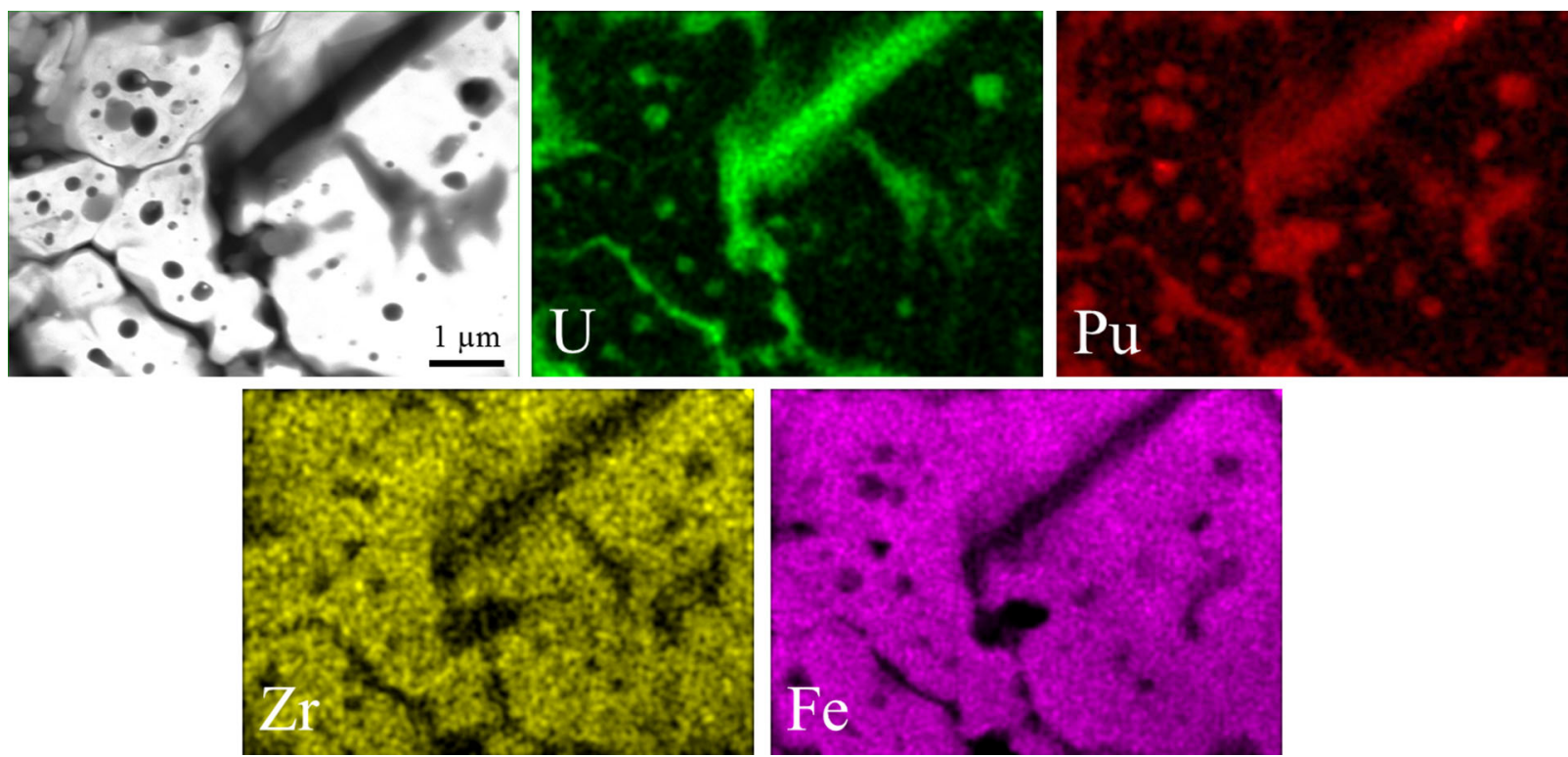

Fig. 6-Scanning transmission electron micrograph and the corresponding X-ray maps of the phases formed in the second lift-out. Scale bar denotes $1 \mu \mathrm{m}$.

Table I. Summary of the Phases Observed Within the FCCI Layer

\begin{tabular}{llll}
\hline Phase & Formula & Space Group & Unit Cell Parameters (nm) \\
\hline $\mathrm{UFe}_{2}$ & $\mathrm{Fe}_{2} \mathrm{U}$ & $\mathrm{Fd}-3 \mathrm{~m} \mathrm{O} 2(227)$ & $a=0.7057$ \\
$\mathrm{ZrFe}_{2}$ & $\mathrm{Fe}_{2} \mathrm{Zr}$ & $\mathrm{Fd}-3 \mathrm{~m} \mathrm{O} 2(227)$ & $a=0.7075$ \\
$\mathrm{PuFe}_{2}$ & $\mathrm{Fe}_{2} \mathrm{Pu}$ & $\mathrm{Fd}-3 \mathrm{~m} \mathrm{O} 2(227)$ & $a=0.7183$ \\
$\alpha-\mathrm{U}$ & $\mathrm{U}$ & $\mathrm{Cmcm}(63)$ & $a=0.2853 ; b=0.5869 ; c=0.4955$ \\
$\beta-\mathrm{Pu}$ & $\mathrm{U}_{0.02} \mathrm{Pu}$ & $\mathrm{C} 12 / \mathrm{m} 1(12)$ & $a=1.1818 ; b=1.0418 ; c=0.7815$ \\
$\beta-\mathrm{Zr}$ & $\mathrm{Zr}$ & $\mathrm{Im}-3 \mathrm{~m} \mathrm{(229)}$ & $a=0.3551$ \\
\hline
\end{tabular}


Figure 6, since the phase has been identified as $\beta$-Pu. The summary of all observed phases is provided in Table I.

Our previous investigation of the phases and microstructure in $\mathrm{U}-\mathrm{Pu}-\mathrm{Zr}$ fuel, with compositions similar to the fuel composition under investigation in this work, showed formation of $\delta-\mathrm{UZr}_{2}, \beta-\mathrm{Pu}$, and $(\mathrm{U}$, $\mathrm{Zr}$ )ht, and $\alpha-\mathrm{Zr}$ precipitates. ${ }^{[20]}$ In the investigation of $\mathrm{U}-23 \mathrm{Pu}-9 \mathrm{Zr}$ fuel, the fuel matrix consisted of $\delta$ - $\mathrm{UZr}_{2}$, $\beta-\mathrm{Pu}$, and $(\mathrm{U}, \mathrm{Zr}) \mathrm{ht}$ phases. ${ }^{[20]}$ Upon annealing of the
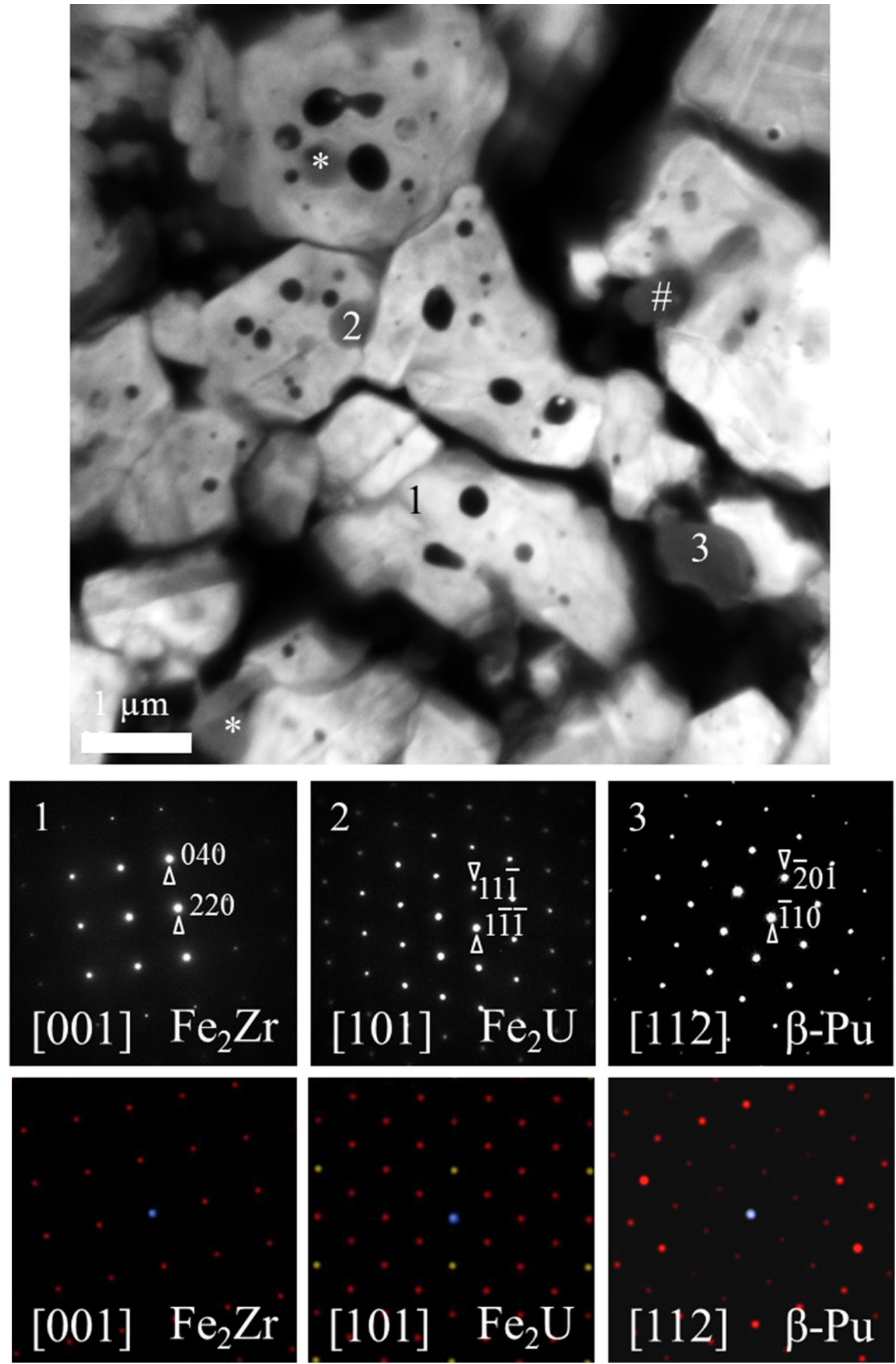

Fig. 7-Transmission electron micrograph acquired from the second lift-out and the corresponding experimental (top row) and simulated SAED patterns (bottom row). Scale bar denotes $1 \mu \mathrm{m}$. The asterisk denotes the location of other identified $\mathrm{Fe}_{2} \mathrm{U}$ phases and the \# denotes the location of $\beta-\mathrm{Pu}$ in the micrograph. 
fuel in contact with the cladding, $\delta$ - $\mathrm{UZr}_{2}$ and $(\mathrm{U}, \mathrm{Zr}) \mathrm{ht}$ phases disappear and only $\beta$-Pu phase remains. However, $\beta$-Pu no longer comprises a majority of the fuel matrix but is present in the form of more or less globular precipitates surrounded by the $\mathrm{Fe}_{2} \mathrm{Zr}$ phase (Figure 7). It is currently impossible to determine the evolution of the matrix phases as we were not able to identify the U-Pu-enriched matrix phase resulting from FCCI. Further work is needed to determine the identity of the matrix phase in the FCCI layer of the diffusion couple.

The phases observed in this work are somewhat similar to those observed in diffusion couple composed of U-19Pu-10Zr fuel and HT-9 cladding. ${ }^{[2]}$ In the work performed by Nakamura, the identified phases were $\mathrm{Fe}_{2} \mathrm{U}, \mathrm{Fe}_{2} \mathrm{Zr}, \varepsilon$, and bcc $+\varepsilon$, where bcc is a solid solution of $\gamma \mathrm{U}+\beta \mathrm{Pu}+\beta \mathrm{Zr}^{\left[{ }^{[21]}\right.}$ Unlike the work conducted by Nakamura, this work used the diffusion couple method to study the FCCI behavior. At the early stages of diffusion, Fick's law governs atom penetration. When the thermal budget is high enough, the concentration profile evolves into step height distributions, with each step corresponding to an equilibrium phase predicted by the phase diagram. A diffusion couple can be formed at a pre-selected temperature and is quickly quenched into to ambient temperature. Thus, the microstructures corresponding to a higher temperature in the phase diagram are retained to a low temperature for characterization (assuming the quench rate is rapid enough), and temperate dependences of phase diagrams can be systematically studied in this way. This method is superior to traditional alloying by mixing metals at given weight percentages, since in diffusion couples, the weight percentages vary from 0 to 100 pet. This method allows validation of existing phase diagram and achieving understanding of local changes in microstructural and microchemistry of each phase.

In the work performed on U-Pu-Zr-Fe alloy, the $\mathrm{Fe}_{2} \mathrm{Zr}, \mathrm{Fe}_{2} \mathrm{U}, \mathrm{Fe}(\mathrm{Pu}, \mathrm{U})_{6}$, a solid solution of $\gamma \mathrm{U}+$ $\beta \mathrm{Pu}+\beta \mathrm{Zr}, \lambda$ phase $\left(\mathrm{Fe}_{0.06} \mathrm{U}_{0.69-0.73} \mathrm{Zr}_{0.21-0.25}\right) \chi$ phase $\left(\mathrm{Fe}_{0.5} \mathrm{U}_{0.18} \mathrm{Zr}_{0.32}\right)$, and $\varepsilon$ phase $\left(\mathrm{Fe}_{0.33} \mathrm{U}_{0.17-0.34} \mathrm{Zr}_{0.33-0.5}\right)$ have been identified. ${ }^{[9]}$ However, since this work has relied on SEM and X-ray data, the variation between reported results is not surprising. In this work, cross-sectional TEM specimens were prepared in the FIB and these specimens show the microstructure of the fuel beyond the surface layer. Since both $\alpha-U$ and $\beta$-Pu phases have been found below the surface of the specimen, these phases may not be detected using surface-based analysis techniques. In addition, differences in casting techniques, starting alloy purities, and thermal histories have to be taken into consideration as all of them can affect the formation of phases.

The significance of these results is that mitigation of life-limiting processes can be greatly enhanced by understanding of fundamental mechanisms of degradation over a wide range of parameters, both in general terms and as a function of specific reactor environment. Detailed and quantitative understanding of atomic scale, in-reactor degradation behavior of nuclear fuels and materials is of critical importance to the development of next generation reactor systems as it is the evolution of the microstructure at the atomic scale which has the most profound impact on bulk properties and in-reactor performance. The FCCI data provided in this work provide the data needed to support multi-scale modeling and simulation efforts of fuels and reactor materials.

\section{SUMMARY}

In this paper, the phases formed between $\mathrm{U}-25 \mathrm{Pu}-14 \mathrm{Zr}$ (wt pct) and Fe have been characterized and identified using transmission electron microscopy. Examination in the scanning electron microscope showed substantial fuel-cladding interaction at $973 \mathrm{~K}$ $\left(700{ }^{\circ} \mathrm{C}\right)$, with the thickness of the FCCI layer in the range of $454 \pm 32 \mu \mathrm{m}$. The phases formed within FCCI layer were identified as $\mathrm{Fe}_{2} \mathrm{U}, \mathrm{Fe}_{2} \mathrm{Zr}, \alpha-\mathrm{U}, \mathrm{Fe}_{2} \mathrm{Pu}, \beta-\mathrm{Pu}$, and $\beta$-Zr. The Pu-U-enriched matrix phase has not been identified using SAD analysis due to differential thinning of diverse phase constituents in FIB. However, in accordance with existing phase diagrams, these phases could correspond to either $\beta \mathrm{U},(\varepsilon \mathrm{Pu}, \gamma \mathrm{U})$, or $(\varepsilon+\mathrm{L})$.

\section{ACKNOWLEDGMENTS}

This work is supported by the U.S. Department of Energy, Office of Nuclear Energy under DOE Idaho Operations Office Contract DE-AC07-05ID14517, as part of Fuel Cycle Research and Development (FCRD) program of US Department of Energy and Nuclear Science User Facilities. The U.S. Government retains a non-exclusive, royalty-free license to publish or reproduce the published form of this contribution, or allow others to do so, for U.S. Government purposes. This information was prepared as an account of work sponsored by an agency of the U.S. Government. Neither the U.S. Government nor any agency thereof, nor any of their employees, makes any warranty, express or implied, or assumes any legal liability or responsibility for the accuracy, completeness, or usefulness of any information, apparatus, product, or process disclosed, or represents that is use would not infringe privately owned rights. References herein to any specific commercial product, process, or service by trade name, trademark, manufacturer, or otherwise, does not necessarily constitute or imply its endorsement, recommendation, or favoring by the U.S. Government or any agency thereof. The views and opinions of authors expressed herein do not necessarily state or reflect those of the U.S. Government or any agency thereof.

\section{REFERENCES}

1. D.E. Burkes, R.S. Fielding, and D.L. Porter: J. Nucl. Mater., 2009, vol. 392, pp. 158-63

2. Y.S. Kim, G.L. Hofman, S.L. Hayes, and Y.H. Sohn: J. Nucl. Mater., 2004, vol. 327, pp. 27-36. 
3. H.J. Ryu, B.O. Lee, S.J. Oh, J.H. Kim, and C.B. Lee: J. Nucl. Mater., 2009, vol. 392, pp. 206-12.

4. D.D. Keiser, Jr and M.C. Petri: J. Nucl. Mater., 1996, vol. 240, pp. 51-61.

5. D.D. Keiser, Jr and M.A. Dayananda: J. Nucl. Mater., 1993, vol. 200 , pp. $229-43$.

6. K. Nakamura, T. Ogata, M. Kurata, A. Itoh, and M. Akabori: $J$. Nucl. Mater., 1999, vol. 275, pp. 246-54.

7. T. Ogata, M. Kurata, K. Nakamura, A. Itoh, and M. Akabori: $J$. Nucl. Mater., 1997, vol. 250, pp. 171-75.

8. A.B. Cohen, H. Tsai, and L.A. Neimark: J. Nucl. Mater., 1993, vol. 204 , pp. $244-51$

9. K. Nakamura, T. Ogata, M. Kurata, T. Yokoo, and M.A. Mignanelli: J. Nucl. Mater., 2002, vol. 304, pp. 63-72.

10. Y. Park, K. Huang, A. Paz y Puente, H.S. Lee, B.H. Sencer, J.R. Kennedy, and Y.H. Sohn: Metal. Mater. Trans. A, 2015, vol. 46A, pp. $72-82$.

11. K. Huang, Y. Park, L. Zhou, K.R. Coffey, Y.H. Sohn, B.H. Sencer, and J.R. Kennedy: J. Nucl. Mater., 2014, vol. 451, pp. $372-78$.
12. P. Stadelmann: JEMS (EMS Java version), CIME-EPFL, Lausanne, 2004.

13. V. Raghavan: J. Phase Equilibria, 2003, vol. 24, pp. 367-74.

14. Y.H. Sohn, M.A. Dayananda, G.L. Hofman, R.V. Strain, and S.L. Hayes: J. Nucl. Mater., 2000, vol. 279, pp. 317-29.

15. R.D. Mariani et al.: Phase Studies and Property Measurements of Some Ternary Fuel Alloys, AFC2-B General Fuel Characterization Report, INL/EXT-09-16781, Idaho National Laboratory, 2009.

16. D.R. O'Boyle and A.E. Dwight: Proceedings of 4th International Conference on Plutonium and Other Actinides, 1970, pp. 720-732.

17. L. Leibowitz et al.: J. Nucl. Mater., 1998, vol. 154, pp. 145-53.

18. C.L. Trybus, J.E. Sanecki, and S.P. Henslee: J. Nucl. Mater., 1993, vol. 204 , pp. $50-55$.

19. D.E. Janney, J.R. Kennedy, J.W. Madden, and T.P. O'Holleran: J. Nucl. Mater., 2014, vol. 448, pp. 109-12.

20. A. Aitkaliyeva, J.W. Madden, C.A. Papesch, and J.I. Cole: $J$. Nucl. Mater., 2015, DOI:10.1016/j.jnucmat.2015.10.043.

21. K. Nakamura, T. Ogata, and M. Kurata: J. Phys. Chem. Solids, 2005 , vol. 66 , p. 643. 